\title{
ESTIMASI PRODUKSI USAHATANI KENTANG (Estimation of Potato Farm Production)
}

\author{
Andi Sawe Ri Esso ${ }^{1}$, Ernawati ${ }^{2}$ \\ ${ }^{1}$ Staf Pengajar Program Studi Manajemen \\ Sekolah Tinggi Ilmu Ekonomi Pembangunan Makassar \\ email : andisaweriesso@yahoo.co.id \\ ${ }^{2}$ Alumni Program Studi Ekonomi Pembangunan \\ Fakultas Ekonomi Universitas Negeri Makassar
}

\begin{abstract}
This study aims to determine the analysis of factors that affect the production of farming. This study uses primary data obtained through direct interviews, analyzed by multiple regression model using SPSS Statistic 21 program. Variables that have an influence on the production of potato farming in this study is Seed Volume has a negative and significant effect on potato production, land area has a positive and significant impact on potato production, and dummy areas have a negative and significant effect on potato production.
\end{abstract}

Keywords: Production of Potato Farming.

\begin{abstract}
Abstrak. Penelitian ini bertujuan untuk mengetahui analisis faktor-faktor yang mempengaruhi produksi usahatani. Penelitian ini menggunakan data primer yang didapat melalui wawancara langsung, dianalisis dengan model regresi berganda menggunakan program SPSS Statistic 21. Variabel yang memiliki pengaruh terhadap produksi usahatani kentang dalam peneltian ini adalah Volume Benih berpengaruh negatif dan signifikan terhadap produksi kentang, luas lahan berpengaruh positif dan signifikan terhadap produksi kentang, dan dummy wilayah berpengaruh negatif dan signifikan terhadap produksi kentang.
\end{abstract}

Kata Kunci : Produksi Usahatani Kentang.

\section{PENDAHULUAN}

Sektor pertanian merupakan sektor strategis dalam pembangunan nasional. Peran sektor pertanian dalam memacu perekonomian dapat dilihat lebih luas terutama dalam konteks mendistribusikan hasil-hasil pembangunan kepada masyarakat di wilayah pedesaan. Sektor pertanian dituntut untuk berperan dalam perekonomian nasional melalui pembentukan produk domestik bruto, perolehan devisa, penyediaan pangan, dan bahan baku industri, pengentasan kemiskinan, penyediaan lapangan kerja, dan peningkatan pendapatan masyarakat. Selain kontribusi langsung, sektor pertanian juga memiliki kontribusi secara tidak langsung berupa dampak pengganda (multiplier effect), yaitu keterkaitan antar input-output antar industry, konsumsi, dan investasi (Rorenkeu, 2005). Peranan sektor pertanian dalam perkembangan perekonomian Indonesia, maka diperlukan adanya suatu upaya pembangunan yang mengarah pada pengembangan sektor pertanian yang tangguh seperti yang dirumuskan dalam visi membangun pertanian periode 20052009, visi pembangunan pertanian 2005-2009 adalah terwujudnya pertanian tangguh untuk pemantapan ketahanan pangan, peningkatan nilai tambah dan daya saing produk pertanian serta peningkatan kesejahteraan petani (Rorenkeu, 2005).

Sulawesi Selatan merupakan salah satu sentra pengembangan kentang di Kawasan Timur Indonesia. Produksi kentang di Indonesia khususnya di Sulawesi Selatan dari tahun 2008 sampai 2010 mengalami penurunan. Sulawesi Selatan merupakan salah satu sentra pengembangan kentang di Kawasan Timur 
Indonesia yang tersebar di dataran tinggi wilayah Kabupaten Gowa, Bantaeng, Enrekang, Tana Toraja, Pinrang, Jeneponto, Luwu Utara, dan Sinjai serta Bone (Badan Pusat Statistik, 2011). Khususnya di Kabupaten Gowa Propinsi Sulawesi Selatan produksi kentang berfluktuasi mulai tahun 2007 sampai tahun 2010 secara berturut-turut: 338,7 ton $(2007) ; 21.301,3$ ton (2008); 3.971,16 ton (2009); dan 12.422 ton (2010). Penyebab penurunan produksi kentang di Indonesia antara lain kurangnya ketersediaan benih bermutu, serangan organisme pengganggu tanaman, teknik budidaya yang kurang sesuai dan anomali iklim.

Gowa merupakan salah satu dari 21 Kabupaten yang berada di Sulawesi selatan. Kapubaten Gowa merupakan salah satu kabupaten di Sulawesi selatan yang memiliki potensi untuk pengembangan sektor pertanian. Salah satu dari lima subsektor pertanian yaitu subsektor hortikultura yang memegang peran yang cukup penting dalam pertanian. Kabupaten Gowa khususnya kecamatan Tinggimoncong merupakan salah satu daerah yang secara agroklimat memenuhi syarat untuk menjadi area pengembangan usahatani kentang karna iklimnya yang sejuk dan berada pada ketinggian lebih dari 1000 meter di atas permukaan laut. Di daerah ini tanaman kentang dapat tumbuh dan berumbi dengan baik karena iklimnya yang cocok dan juga karena kondisi tanahnya yang subur serta gembur.

Kecamatan Tinggimoncong merupakan salah satu sentra produksi sayur-sayuran di Kabupaten Gowa diharapkan mampu berperan dalam pengembangan hortikultura khususnya sayura-sayuran ditingkat kabupaten Gowa. Kentang sebagai produk yang termasuk dalam kategori sayur-sayuran juga diharapkan mampu

$$
\mathrm{Y}=\mathrm{f}\left(\mathrm{X}_{1}, \mathrm{X}_{2}, \mathrm{X}_{3}, \ldots, \mathrm{X}_{\mathrm{n}}\right)
$$

Untuk mengetahui sejauh mana pengaruh faktor produksi terhadap produksi kentang di Kecamatan Tinggimoncong Kabupaten Gowa

$$
\begin{aligned}
& \mathrm{Pkn}=\beta_{0} \quad \mathrm{Vpu}^{\beta 1} \quad \mathrm{Bnh}^{\beta 2} \quad \text { Vpnpk }{ }^{\beta 3} \mathrm{Jtk}^{\beta 4} \quad \text { Llhn }{ }^{\beta 5} \quad \mathrm{Umr}^{\beta 6} \operatorname{Pber}^{\beta 7} \operatorname{Pend}^{\beta 8} \quad \mathrm{DmW}^{\mathrm{d} 1} \\
& \mathrm{e}^{1} \text {... }
\end{aligned}
$$

Untuk menggunakan model persamaan

(2) maka persamaan tersebut diubah menjadi

bentuk linear berganda dengan cara melogaritmakan sebagai berikut:

$$
\begin{aligned}
\operatorname{LnPkn}= & \operatorname{Ln} \beta_{0}+\beta_{1} \operatorname{LnVpu}+\beta_{2} \operatorname{LnBnh}+\beta_{3} \operatorname{LnVpnpk}+\beta_{4} \operatorname{LnJtk}+ \\
& \beta_{5} \text { LnLlhn }+\beta_{6} \operatorname{LnUmr}+\beta_{7} \operatorname{LnPber}+\beta_{8} \text { LnPend }+\mathrm{d}_{1} \text { DmW }+\mathrm{e}
\end{aligned}
$$

dimana:

Pkn $\quad=$ Produksi kentang $(\mathrm{kg})$ 


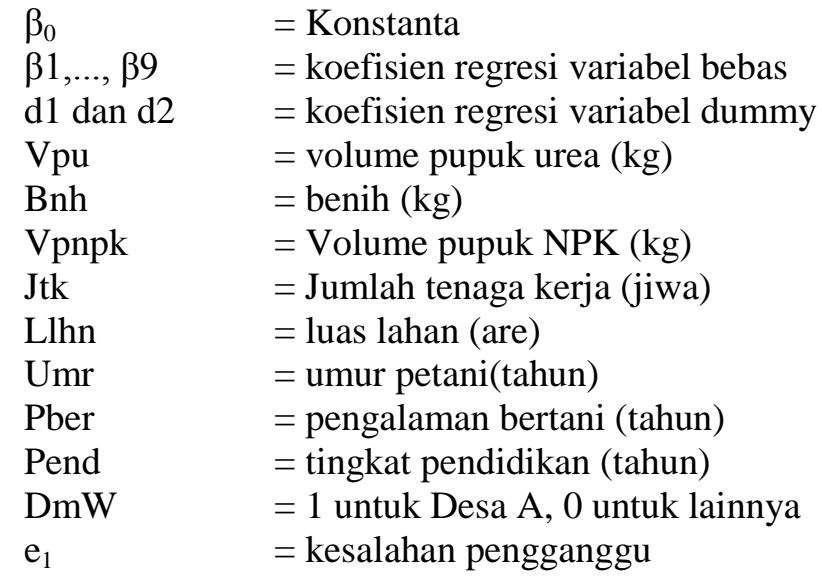

Uji F (uji simultan) digunakan untuk uji signifikansi model, termasuk untuk mengetahui faktor-faktor yang mempengaruhi produksi

$$
\mathrm{Yi}=\beta_{0}+\beta_{1} \mathrm{X}_{1}+\beta_{2} \mathrm{X}_{2}+\mathrm{ei}
$$

Dimana koefisien determinasi: TSS $=$ ESS + SSR, TSS mempunyai df $=\mathrm{n}-1$, ESS mempunyai $\mathrm{df}=\mathrm{k}-1$ dan SSR mempunyai $\mathrm{df}=$ $\mathrm{n}-\mathrm{k}$. Analisis varian adalah analisis dekomposisi komponen TSS.

$$
\begin{aligned}
& \mathrm{F} \text { hit }=\frac{\mathrm{ESS} /(\mathrm{k}-1)}{\mathrm{RSS} /(\mathrm{n}-\mathrm{k})} \text {. } \\
& \text { F tabel }\{(\mathrm{k}-1):(\mathrm{n}-\mathrm{k}) ; \alpha / 2\} \\
& \text { dimana: } \\
& \mathrm{k}=\text { = jumlah variabel tidak termasuk intercept } \\
& \mathrm{n} \quad=\text { jumlah sampel } \\
& \text { ESS = jumlah kuadrat dapat dijelaskan } \\
& \text { RSS = residual jumlah kuadrat tidak dapat dijelaskan } \\
& \alpha=\text { tingkat signifikan atau kesalahan tertentu }
\end{aligned}
$$

Uji $\mathrm{t}$ digunakan untuk mengetahui keberartian masing-masing faktor pengeluaran petani terhadap tingkat produksi kentang, apakah masing-masing variabel independen mempunyai pengaruh seacara signifikan terhaap variabel dependen. Uji $\mathrm{t}$ digunakan untuk membuat

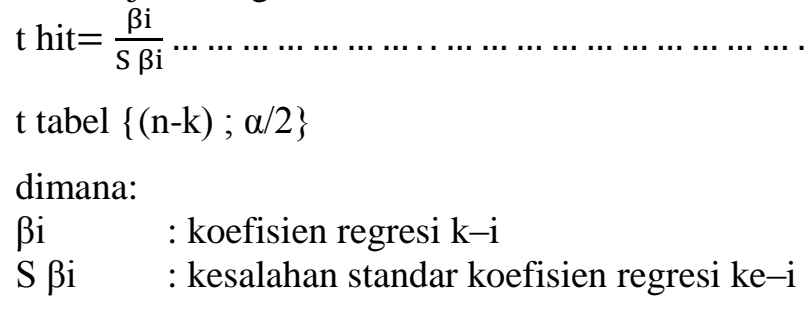

Pengukuran Ketepatan atau kesesuaian model (goodness of fit) dilakukan dihitung melalui $\mathrm{R}^{2}$ dan Adjusted $\mathrm{R}^{2}$.

Nilai $\mathrm{R}^{2}$ selalu meningkat dengan bertambahnya variabel independen dari suatu model, hal tersebut menjadi kelemahan $\mathrm{R}^{2}$.

keputusan apakah hipotesis terbukti atau tidak, dimana tingkat signifikansi yang digunakan 5\% dan pengujian terhadap koefisien regresi secara individu (persial) digunakan uji t dengan tingkat kepercayaan dengan rumus:

$$
\text { Adjusted } \mathrm{R}^{2}=1-\left(1-\mathrm{R}^{2}\right) \frac{(\mathrm{n}-1)}{(\mathrm{k}-1)}
$$


di mana :

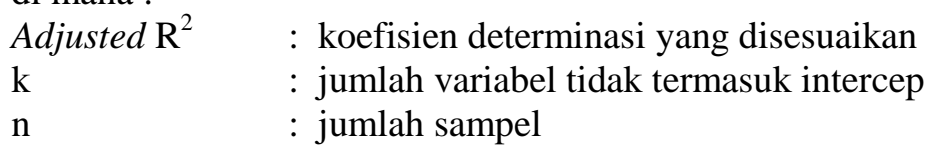

Menurut Singgih Santoso (Asisi, 2014) suatu model regresi yang bebas dari multikolinearitas apabila mempunyai nilai VIF lebih kecil dari 10 dan nilai tolerance tidak kurang dari 0,1 . Penelitian ini menggunakan

$$
\mathrm{VIF}=\frac{1}{1-\mathrm{R}^{2}} \ldots \cdots
$$

Pengujian heteroskedastisitas (heteroscedasticity) yang terjadi bila tidak konstannya varians di setiap titik regresi sehingga mengakibatkan nilai kesalahan

$\mathrm{E}\left({\mu_{\mathrm{t}}}^{2}\right)=\sigma_{\mathrm{i}}^{2}$

Dengan hipotesis :

$\mathrm{H}_{0}: \sigma^{2}=0$, artinya homokedastisitas

$\mathrm{H}_{1}: \sigma^{2} \neq 0$, artinya terdapat heteroskedastisitas

Masalah heteroskedastisitas lebih banyak terjadi pada data cross section dibandingkan data time series (Rahim, 2012). Akibatnya walaupun estimasi parameter regresi masih unbiased, tetapi tidak efisien dan tidak konsisten (Hartono, 2009). Persamaan tidak dapat digunakan ketika

$$
\begin{aligned}
& \operatorname{Ln} \hat{\mathrm{e}}_{\mathrm{i}}{ }^{2}=\operatorname{Ln} \sigma^{2}+\beta \operatorname{Ln} X_{\mathrm{i}}+\mathrm{v}_{\mathrm{i}} \\
& =\alpha+\beta \operatorname{Ln} X_{i}+\mathrm{v}_{\mathrm{i}} \ldots \ldots \ldots \ldots \ldots
\end{aligned}
$$

Keputusan ada tidaknya masalah heterokedastisitas berdasarkan uji estimator $(\beta)$ dengan meregres Ln $\hat{\mathrm{e}}_{\mathrm{i}}{ }^{2}$ dengan masing-masing Ln variabel independen. Mengemukakan jika koefisien ( $\beta$ ) tidak signifikan melalui uji t, maka dapat disimpulkan tidak terdapat heteroscedasticity atau homoscedasticity karena varian residualnya tidak tergantung dari variabel variance inflation factor (VIF) yang terdapat pada program statistical program for service solution (SPSS). Menurut Gujarati (Rahim 2012) dirumuskan: pengganggu atau error $(\mu)$ meningkat. Menurut Gujarati, Greene, Studenmund (Rahim, 2012) kejadian varians dari kesalahan pengganggu tidak konstan yang dilambangkan:

varian variabel gangguan $\left(\sigma_{i}^{2}\right)$ tidak diketahui sehingga Park menyarankan menggunakan residual $\left(\hat{\mathrm{e}}_{\mathrm{i}}{ }^{2}\right)$ hasil regresi sebagai proxy dari residual $\hat{\mathrm{e}}_{\mathrm{i}}^{2}$ (Rahim, 2012). Persamaannya sebagai berikut:

\begin{tabular}{|c|c|c|}
\hline Desa & $\begin{array}{c}\text { Produksi } \\
(\mathrm{Kg})\end{array}$ & $\begin{array}{l}\text { Produksi Rata-Rata } \\
\qquad(\mathrm{Kg})\end{array}$ \\
\hline Pattapang & 19.450 & 389,00 \\
\hline Bulutana & 14.320 & 286,40 \\
\hline Total & 33.770 & 675,40 \\
\hline
\end{tabular}

Tabel 1. Produksi Responden Petani kentang di Desa Pattapang dan Desa Bulutana Kecamatan Tinggimoncong Kabupaten Gowa.

Sumber :Data primer setelah (diolah,2016)

Berdasarkan Tabel 1, menunujukkan bahwa desa yang memiliki produksi tertinggi yaitu Desa Pattapang dengan jumlah produksi sebesar $19.450 \mathrm{~kg}$ dengan produksi rata-rata independen, sebaliknya jika $\beta$ signifikan secara statistik maka model mengandung unsur heteroscedasticity karena besar kecilnya varian residual ditentukan oleh variabel independen (Rahim, 2012).

\section{HASIL DAN PEMBAHASAN}

Analisis produksi usahatani kentang dapat dilihat pada tabel 1 . 
produksi di Desa Pattapang lebih besar dari Desa Bulutana karena tanahnya lebih subur.

Pembahasan ini peneliti ingin mengetahui variabel-variabel apa saja yang mempengaruhi produksi usahatani kentang, oleh karena itu peneliti menggunakan sembilan variabel, adapun variabel tersebut diantaranya volume pupuk urea, benih, volume pupuk NPK, jumlah tenaga kerja, luas lahan, umur petani, pengalaman bertani, tingkat pendidikan dan dummy desa Pattapang dan dummy desa Bulutana. Terdapat faktor yang mempengaruhi secara langsung yaitu pupuk urea, benih, pupuk NPK, jumlah tenaga kerja, luas lahan dan faktor yang mempengaruhi secara tidak langsung yaitu, umur, pengalaman bertani, tingkat pendidikan, dan dummy wilayah.

Hasil uji multikolinearitas dengan metode variance inflaction factor (VIF) tidak menunjukkan atau mengondisikan terjadi multikolinearitas atau kolinearitas ganda, dengan kata lain tidak ada variabel yang saling berpengaruh satu sama lain. Karena nilai VIF masing-masing variabel lebih kecil dari pada 10 hal ini dapat dilihat pada Tabel 2.

Sementara pengujian heterokedastisitas dengan aplikasi SPSS menggunakan metode Park test, yaitu variabel error sebagai dependen variable diregres dengan setiap variabel independen dan menghasilkan nilaikoefisien $(\beta)$ tidak signifikan maka dapat disimpulkan tidak terdapat heteroscedasticity.

Heteroskedasitas merupakan fenomena terjadinya perbedaan varian antar seri data. Heteroskedasitas muncul apabila nilai varian dari variabel tak bebas (Yi), meningkat sebagai meningkatnya varian dari variabel bebas (Xi), maka varian dari Yi adalah tidak sama. Gejala heteroskedasitas lebih sering dalam data croos sectiondari pada time series.Selain itu juga sering muncul dalam analisis yang menggunakan data rata-rata.

Tabel 2. Analisis faktor-faktor yang mempengaruhi produksi kentangdi Desa Pattapang dan Desa BulutanaKecamatan Tinggimoncong Kabupaten Gowa.

\begin{tabular}{|c|c|c|c|c|c|c|}
\hline \multirow{2}{*}{ Variabel Independen } & \multirow{2}{*}{ T.H } & \multirow{2}{*}{ B } & \multirow{2}{*}{ t-Hit } & \multirow{2}{*}{ Sig } & \multicolumn{2}{|c|}{ Uji Asumsi Klasik } \\
\hline & & & & & VIF & park Test \\
\hline Volume Pupuk Urea & + & $0.077 \mathrm{~ns}$ & 0.491 & 0.626 & 9.795 & 0.838 \\
\hline Volume Benih & + & $-0.466 * *$ & -2.504 & 0.016 & 9.832 & 0.975 \\
\hline Volume Pupuk NPK & + & $0.090 \mathrm{~ns}$ & 1.015 & 0.316 & 4.074 & 0.099 \\
\hline Jumlah Tenaga Kerja & & $-0.033 n s$ & -0.478 & 0.635 & 1.402 & 0.482 \\
\hline Luas Lahan & + & $1.393 * * *$ & 7.518 & 0.000 & 7.109 & 0.999 \\
\hline Umur & - & $0.148 \mathrm{~ns}$ & 0.773 & 0.444 & 7.475 & 0.525 \\
\hline Pendidikan & + & $-0.035 \mathrm{~ns}$ & -0.434 & 0.667 & 1.589 & 0.272 \\
\hline Pengalaman Bertani & + & $-0.003 \mathrm{~ns}$ & -0.023 & 0.982 & 8.139 & 0.326 \\
\hline Dummy Wilayah & + & $-0.092 *$ & -1.892 & 0.066 & 1.571 & 0.816 \\
\hline Konstanta & & & & & & 1.870 \\
\hline F hitung & & & & & & 42.256 \\
\hline Adjusted $\mathrm{R}^{2}$ & & & & & & 0.883 \\
\hline $\mathrm{N}$ & & & & & & 50 \\
\hline
\end{tabular}

Sumber :Data primer setelah (diolah,2016)

Keterangan :

TH : Tanda harapan

*** : Taraf signifikansi dan kesalahan 0,01 (1 persen) atau tingkat kepercayaan 99 persen.

** : Taraf signifikansi dan kesalahan 0,05 (5 persen) atau tingkat kepercayaan 95 persen.

* : Taraf signifikansi dan kesalahan 0,10 (10 persen) atau tingkat kepercayaan 90 persen.

ns : Tidak signifikan

VIF : jika nilai VIF lebih kecil dari 10 maka tidak terdapat multikolinearitas, sebalikmya jika nilai VIF lebih besar dari 10 maka terjadi multikolinearitas

Park : Tidak signifikan; jika nilai $\beta$ tidak terdapat heterokedastisitas, sebaliknya jika nilai $\beta$ signifikan, maka terdapat heterokedastisitas. 
Pengukuran ketepatan atau kesesuaian model (goodness of fit) dilakukan atau dihitung menggunakan Ajusted $\mathrm{R}^{2}$ yang menunjukkan variabel independen sebesar 0.883 , berarti variansi faktor produksi pupuk urea, pupuk benih, pupuk NPK,jumlah tenaga kerja, luas lahan, umur, pendidikan,pengalaman bertani,dan dummy wilayah memberikan kontribusi $88.3 \%$ terhadap produksi kentang di Desa Pattapang dan Desa Bulutana Kecamatan Tinggimoncong Kabupaten Gowa, sedangkan sisanya $11,7 \%$ dipengaruhi oleh faktor yang tidak diperhatikan dalam model.

LnPkn $=$ Ln1.870+ 0.077LnVpu $-0.466 \mathrm{LnBnh}+0.090$ VPnpk $-0.033 \mathrm{LnJtk}+1.393 \mathrm{LnLlhn}+$ 0.148LnUmr $\quad-\quad 0.035$ LnPend $\quad-0.003$ LnPber $-0.092 \quad$ LnDw $\quad+$ Lne.

Dari persamaan (IV.1) maka persamaan tersebut diubah kembali dalam fungsi produksi

$$
\begin{aligned}
& \text { Pkn= anti Ln1.870 } \mathrm{Vpu}^{0.077} \mathrm{Bnh}^{-0.466} \mathrm{VPnpk}^{0.090} \mathrm{Jtk}^{0.033} \mathrm{Llhn}^{1.393} \mathrm{Umr}^{-0.148} \\
& \text { Peng }{ }^{-0.035} \mathrm{Dw}^{-0.092} \mathrm{e}^{\mu} \\
& =6.489 \mathrm{Vpu}^{0.077} \mathrm{Bnh}^{-0.466} \mathrm{VPnpk}^{0.090} \mathrm{Jtk}^{0.033} \mathrm{Llhn}^{1.393} \mathrm{Umr}^{-0.148} \text { Pber }^{-0.035} \\
& \mathrm{Dw}^{-0.092} \mathrm{e}^{\mu} \text {. }
\end{aligned}
$$

Cobb-Douglas dengan meng-anti Ln kan sebagai berikut: signifikan terhadap produksi kentang adalah volume benih, luas lahan dan dummy wilayah sedangkan untuk Variabel yang tidak berpengaruh signifikan terhadap produksi kentang adalah Volume pupuk urea, volume pupuk NPK, jumlah tenaga kerja, umur,

Berdasarkan hasil analisis regresi maka

dihasilkan persamaan regresi berikut :
Nilai intersep/kostanta sebesar 6,489 pada fungsi produksi kentang menunjukkan bahwa tanpa variabel independen yaitu volume pupuk urea, volume benih, volume pupuk NPK, jumlah tenaga kerja, luas lahan, umur, pendidikan, pengalaman bertani dan Dummy wilayah maka produksi kentang naik sebesar $6.489 \mathrm{~kg}$.

Untuk mengetahui keberartian koefisien regresi maka dilakukan uji $\mathrm{F}$, adapun uji $\mathrm{F}$ yang dimaksud dapat dilihat pada Tabel 2 yang menunjukkan bahwa nilai Fhitung sebesar42.256atau lebih besar dari F tabel, yaitu sebesar 3.099 dengan signifikansi 0.000 jauh lebih kecil dari taraf signifikan yang digunakan dalam peneitian ini yaitu 0.01 atau $1 \%$.Dengan demikian dapat disimpulkan pengujian hipotesis diatas menolak $\mathrm{H}_{0}$ atau menerima $\mathrm{H}_{1} \mathrm{Hal}$ ini menunjukkan bahwa volume pupuk urea, benih, volume pupuk NPK, jumlah tenaga kerja,luas lahan, umur, pendidikan, pengalaman bertani, dan dummy wilayah secara simultan mempunyai pengaruh yang signifikan terhadap produksi kentang di Kecamatan Tinggimoncong Kabupaten Gowa.

Untuk mengetahui tingkat produksi mana saja yang mempunyai pengaruh dan bermakna signifikan terhadap hasil produksi usahatani kentang di Kecamatan Tinggimoncong
Kabupaten Gowa dilakukan Uji t, berikut variabel yang memiliki pengaruh signifikan terhadap hasil produksi usahatani kentang dalam penelitian ini:

Berdasarkan hasil penelitian ini menunjukkan bahwa Volume Benih berpengaruh negatif dan signifikan terhadap produksi kentang. Hal ini dapat dilihat pada tabel 4.11 menunjukkan nilai t hitung sebesar -2.504 lebih kecil dari t tabel 2,698 dan berarti $\mathrm{H}_{0}$ ditolak $\mathrm{H}_{1}$ diterima dengan tingkat signifikansi 0.016 lebih besar dari taraf signifikansi yang digunakan dalam penelitian ini yaitu 1 persen atau 0.01 sehingga diartikan bahwa Volume benih berpengaruh signifikan terhadap produksi kentang di Kecamatan Tinggimoncong. Koefisien regresi sebesar -0.466 yang berarti penambahan volume benih sebesar $1 \mathrm{~kg}$ akan mengurangi tingkat produksi kentang sebesar $0.466 \mathrm{~kg}$. Rata-rata benih yang digunakan di Desa Pattapang dan Desa Bulutana sebesar $239,8 \mathrm{~kg}$.

Selanjutnya hasil penelitian menunjukkan bahwa luas lahan berpengaruh positif dan signifikan terhadap produksi kentang. Hal ini dilihat pada tabel 4.11 menunjukkan bahwa nilai $\mathrm{t}$ hitung sebesar 7.518 dengan tingkat signifikansi sebesar 0.000 yang jauh lebih kecil 
dari taraf signifikansi yang digunakan yaitu 1 persen (0.01). Dilihat dari nilai t hitung sebesar 7.518 lebih besar dari t tabel 2.719 yang berarti bahwa $\mathrm{H}_{0}$ ditolak dan $\mathrm{H}_{1}$ diterima. Koefisien regresi sebesar 1.393 menunjukkan bahwa penambahan luas lahan 1 hektar akan meningkatkan produksi kentang sebesar 1.393 Are. Rata-rata luas lahan yang digunakan di Desa Pattapang dan Desa Bulutana sebesar 65 are. Hal ini sejalan dengan tanda harapan yang artinya semakin luas lahan yang dimiliki seorang petani, maka akan menambah jumlah produksi kentang.

Berdasarkan hasil penelitian menunjukkan bahwa Dummy Wilayah berpengaruh negatif dan signifikan terhadap produksi kentang. Hal ini dilihat pada tabel 4.11 menunjukkan bahwa nilai t hitung sebesar 1.892 dengan tingkat signifikansi sebesar 0.066 lebih besar dari taraf signifikansi yang digunakan yaitu 1 persen (0.01). Dilihat dari nilai $t$ hitung sebesar 1.892 lebih besar dari $t$ tabel 2.719 yang berarti bahwa $\mathrm{H}_{0}$ ditolak dan $\mathrm{H}_{1}$ diterima. Koefisien regresi sebesar -0.092 menunjukkan bahwa penambahan dummy wilayah akan mengurangi produksi kentang sebesar 0.092 persen.

\section{DAFTAR RUJUKAN}

Afifah, 2011. Penanganan Penyimpangan Kentang Bibit (Solanum Tuberosum L) di Himah Farm, Pangalengan, Bandung, Jawa Barat.Skripsi tidak dipublish. Institut Pertanian Bogor. www.google.com (diakses 10 oktober 2015).

Arifatus.Ana. 2011. Kajian ekonomi usahatani kentang di kecamatan Sukapura, Kabupaten Probolinggo. Jurnal. Universitas Tribhuwana Tunggadewi. www.google.com (diakses 10 0ktober 2015)..

Badan Pusat Statistik Gowa, Kabupaten Gowa dalam angka 2009-2013,BPS

Bowo.Tri, 2010. Analisis faktor-faktor yang mempengaruhi produksi kentang, studi kasus Desa Betokan, Kecamatan Demak, Kabupaten Demak. Skripsi tidak dipublish. Universitas Diponegoro Semarang. www.google.com (diakses 5 oktober 2015).

\section{SIMPULAN DAN SARAN}

Dalam penelitian ini faktor-faktor yang mempengaruhi produksi kentang di Kecamatan Tinggimoncong Kabupaten Gowa yang berpengaruh signifikan produksi kentang adalah benih, luas lahan, dan dummy wilayah yang berpengaruh tidak signifikan produksi kentang yaitu volume pupuk urea, volume pupuk NPK, jumlah tenaga kerja, umur petani, pengalaman bertani, dan tingkat pendidikan

Diharapkan dari pemerintah setempat agar semakin meningkatkan adanya pembinaan penyuluhan pertanian mengenai budidaya dan peningkatan hasil produksi usahatani kentang dalam rangka peningkatan kesejahteraan masyarakat petani terkhusus petani kentang sehingga dapat meningkatkan pula produksi yang dihasilkan oleh petani kentang di Kecamatan Tinggimoncong Kabupaten Gowa. Dalam kesempatan ini penulis menyarankan kepada peniliti selanjutnya untuk mengidentifikasi faktor-faktor lain yang mempengaruhi produksi kentang yang lebih lengkap. Karena keterbatasan jumlah variabel yang digunakan dalam penelitian ini.

Dinas pertanian Kabupaten Gowa . 2014. Data Areal Jumlah Produksi Dan luas tanam Tanaman hortikultura.

Magfirah.Sri, 2011. Analisis faktor-faktor yang mempengaruhi produksi dan pendapatan usahatani kelapa sawit di Kecamatan Tomoni Kabupaten Luwu Timur. Skripsi tidak dipublikasikan. Makassar. Program Studi Ekonomi Pembangunan Universitas Negeri Makassar.

Nurcaya. 2014. Analisis faktor-faktor yang mempengaruhi produksi kentang di kabupaten bantaeng. Skripsi tidak dipublish, Universitas Negeri Makassar

Rahim, Abd. 2012. Model Analisis Ekonomika Pertanian. Badan Penerbit UNM ,Makassar

Rahim, Abd, 2012. Model Ekonometrika Perikanan Tangkap. . Badan Penerbit UNM ,Makassar

Risky, 2013. Analisis usaha tani kentang di Desa Gantarang Kecamatan Tinggimoncong Kabupaten Gowa. Skripsi tidak dipublikasikan. Makassar: Program 
Studi Agribisnis Universitas

Hasanuddin.

Raronkeu, 2005. Pengantar Ekonomi Pertanian.

www. Goegle.com (Diakses 08

oktober 2015).

Sugiyono, 2014. Metode penelitian kuantitatif kualitatif dan $R \& D$, Penerbit Alfabeta.

Bandung. 